\title{
ERRATUM
}

Jens-Olaf Beismann · Bernard Barnier

\section{Variability of the meridional overturning circulation of the North Atlantic: sensitivity to overflows of dense water masses}

Received: 4 July 2003 / Accepted: 17 December 2003

(C) Springer-Verlag 2004

\section{Ocean Dynamics (2004) 54: 92-106}

Due to a technical problem in the publication process figure 8 of the above mentioned article has not been published correctly. Please find the correct version on the right hand side.

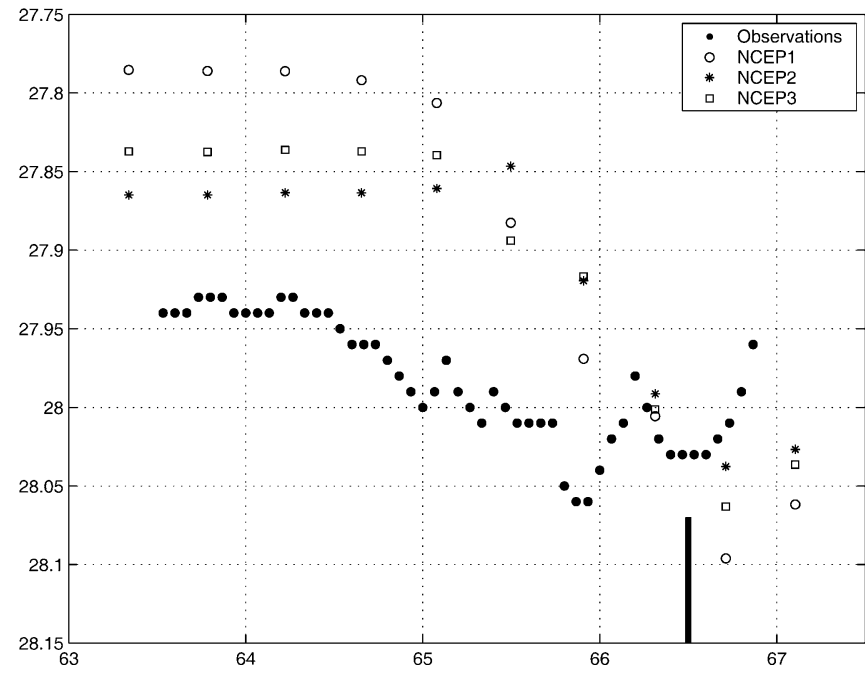

Fig. 8 Maximum of the potential density $\sigma_{0}$ as a function of latitude close to the sills between the subpolar gyre and the Nordic Seas. Observations are a compilation of cruise data sampled between 1996 and 1999 (Käse et al. 2003). The latitude of Denmark Strait is marked by the thick line

J.-O. Beismann $(\bowtie)$

NEC High Performance computing

Europe GmbH, Prinzenallee 11,

40549 Düsseldorf, Germany

e-mail: jobeismann@web.de

B. Barnier

Laboratoire des Ecoulements Géophysiques et Industriels,

BP 53 X, 38041 Grenoble cedex 9, France 